\title{
Self-Concepts and Parental Reports on Children's Social Skills at Home
}

\author{
Haibin Li \\ Faculty of Education and Social Work, University of Sydney \\ NSW 2006 Australia \\ Tel: 61-2-9036-5300Ｅ-mail: haibin.li@edfac.usyd.edu.au \\ Laurel Bornholt (Corresponding author) \\ Watervale Systems \\ PO Box 318 Potts Point, Australia NSW 1335 Australia \\ Tel: 61-2-9357-2310 E-mail: laurelbau@yahoo.com.au
}

\begin{abstract}
Social behaviours are critical to children's developmental outcomes, yet the evidence may be difficult to interpret from either child self-report or reports by other people. We propose that any distinctions and commonalities among parent and child reports depend on content and context. The materials were reliable indicators of self-concepts and parent reports on children's social behaviour at home from the Rowe Behaviour Rating Inventory. Participants were four- to thirteen-year-old girls and boys, and the parents or primary care-givers, in a selected location close to the Australian national average in socio-economic indicators. Results show that child self-reports and parent reports were generally not associated. The findings support the contextual hypothesis of distinct perspectives by parents and children. Findings also contribute to knowledge of children's social self concepts that has practical considerations for health and education programmes. We conclude that it would be worthwhile to extend this work on dimensions of children's social behaviour at home to cover other behaviours and the perspectives by other key people across diverse socio-economic locations.
\end{abstract}

Keywords: Motivation and self-concept, Parent-child responsiveness, Social behaviour

\section{Introduction}

Investigations across disciplines in social sciences provide strong yet diverse foundations for the study of self. Increasingly, these so called 'self-concepts' are considered as cognitive self-evaluations in relation to particular characteristics, events and activities (e.g., Merrell, Cedeno, \& Johnson, 1993; Zentner \& Renaud, 2007). The classic work of William James from 1890 related the self-concept to behaviour - as an interpretation of experiences, where self concepts in turn support expectations of events. For instance, Bornholt and Piccolo (2005) suggest spiralling links between children's self-concepts and behaviours that motivate participation in learning and social activities. This paper takes up the implications for professionals who work with children on social behaviours: we need to consider the children's self-concepts about social behaviours as an addition to their actual behaviour and experiences.

It is clear that people's skills and abilities are best assessed by appropriate tests and observations (see Gresham, 1986). In addition, indicators of self-concepts require responses by the person about the particular events, characteristics and activities (see Bornholt, 2005). Ongoing research emphasises that it is particularly important to consider assessment situations when working with children, and many available inventories are unreliable, particularly for young children (see Davis-Kean \& Sandler, 2001). Some researchers argue that children may lack the necessary cognitive capacity to respond in a valid way to self-concept inventories (e.g., Cook \& Douglas, 1998) although others disagree (see Russell, Bornholt, \& Ouvrier, 2002). Recent research confirms that with well-designed inventories, children as young as four or five years old can distinguish among aspects of self-concepts (see Bornholt, 2005; Brown, Mangelsdorf, Agathen, \& Ho, 2008; Marsh et al., 2005; Moretti, Fine, Haley, \& Marriage, 1985).

A long-standing debate rests on whether self-concepts about behaviour may or may not be substituted by observations by other people - where content and context are critical dimensions (see Achenbach et al., 1987). For instance, early reports by Herjanic, Herjanic, Brown and Wheatt (1975) indicated strong agreement (on average 80\%) between parent 
ratings and child self-reports on factual information (e.g., age, address, reason for coming, and source of referral) as well as psychiatric symptoms such as phobias, obsessions, somatic complaints and symptoms. Other studies of educational content (e.g., reading, mathematics, appearance and peer relations), suggest that some self-concepts reported by significant others (including parents and teachers) seemed to agree reasonably well with child self-concepts (Marsh \& Craven, 1991). Yet the balance of evidence suggests that child self concepts and observations by others are not mistaken in any lack of agreement, but instead highlight the particular perspectives by each person; that are not necessarily systematically related (also see Shrauger \& Schoeneman, 1979 for a review). This contextual approach was highlighted by Achenbach and colleagues (1987). The meta-analysis of 119 studies to focus on broadly defined behaviour problems included ratings by many informants (e.g., parents, teachers, mental health workers, observers, peers and the children) with weak links between child-other informant ratings $(r=.22)$. Yet many practitioners continue to use parent reports to stand in for home observations or child self reports. On this point, a recent study by Brown et al. (2008) also showed limited associations between reports on the child's personality by mothers and children.

It would seem that content and context are important considerations here. The other problem is a sustained focus on particular problem behaviours; too few studies consider full dimensions of children's social skills at home. Our study therefore used parental reports in a reliable inventory, the Rowe Behaviour Rating Inventory (RBRI, Rowe \& Rowe, 1997) and adapted the ASK-KIDS inventory (Bornholt, 2005) to provide matching self report to indicate children's social behaviour at home. It is important to reject the common practice of using the parent reports to stand in for child self reports. We designed the study to account for two plausible explanations for possible discordant views in the literature. The first explanation is that some areas of self-concepts (without reference to particular events) may resemble aspects of personality - this content may be inherently more difficult for other people to know. The second explanation is more practical. Perhaps apparent agreement between parent and child is necessarily altered where non-parallel dimensions were used in self-concepts and observation.

There can be no doubt that acceptable social behaviours are one of the foundations for children's interactions with others and later development. Therefore, many practical programs aim to build children's social skills. Indeed, Harter (1988) suggests positive self-concepts about behaviours are associated with many intra- and inter-personal developmental outcomes.

We focused our attention on children's social behaviour at home because children's behaviour may be quite distinct at home and at school. On this point, Linder (1993) suggests that at home children may be more likely to demonstrate a full range of behaviours from their behavioural repertoires. The location of this study in the home therefore complements the wealth of research with children in schools (e.g., Hoy et al., 1992; Merrell et al., 1993). Although social behaviour at home also influences children's opportunities for learning and development, few studies of social behaviour include direct observation of children's behaviours at home (see Bornholt \& Rhodes, 2006; Prior, Smart, Sanson, Pedlow, \& Oberkaid, 2001; Stormont, 2001).

The study was designed to test two main hypotheses about self-concepts and observation, that children and parents express generally positive ideas about aspects of social behaviour, and that child self-reports and parental reports are distinct rather than agree as perspectives-in-common.

\section{Method}

\subsection{Design}

The study was in a selected location to control broad factors of socio-economic indicators. The correlational design was used to examine the evaluations by parents and the children themselves regarding three related continua of children's social behaviour at home (unsociable-sociable, inattentive-attentive, restless-settled behaviour). These behaviours were selected because they influence children's opportunities for development (Cremeens, Eiser, \& Blades, 2006).

\subsection{Participants}

The sample included children from pre-school, kindergarten, Year 1 to Year 6 at school in a suburban area close to the national average in socio-economic indicators (Socio-Economic Index For Areas, SEIFA $=1005$, where 1000 is the national average, see Australian Bureau of Statistics ABS., 2006). The participants ( $\mathrm{N}=80)$ in this study included 40 children ( 25 boys, 15 girls) between the ages of 4 and 13, as well as the available parents or primary care-givers for each child ( $\mathrm{N}=40$, men 6 , women 34$)$.

\subsection{Instruments}

Child self-reports based on ASK-KIDS (Bornholt, 1997; 2005) and Rowe Behaviour Rating Inventory (RBRI, 1995, 1997) were adapted for this study with the permission of the authors (Bornholt and Rowe, respectively).

Parent reports of child's social behaviour. The Rowe Behaviour Rating Inventory, RBRI (Rowe \& Rowe, 1995, 1997) includes parent and teacher evaluations about children's social behaviour at home and school. The RBRI includes three related social behaviours along continuous dimensions (unsociable-sociable 5 items, inattentive-attentive 4 items, 
restless-settled 3 items). Each item is anchored by a negative and a positive behavioural statement, and allows one of five dot responses. Parent responses formed reliable scale with unweighted items (Cronbach alpha coefficients $>0.7$ for each scale). Scores for parental reports on children's behaviour at home range from (1) unsociable (e.g., disputes, fights over sharing) to (5) sociable behaviour at home (e.g., co-operative; shares with others).

Children's self-concepts about social behaviour. Presentation of the RBRI parent-form was adapted for children's self-report about social behaviour at home. The form was based on sound practice in eliciting self concepts in the ASK-KIDS Self Concept Inventory for Children (Bornholt, 1997, 2005). The same 12 statements from the RBRI parent-form about the child's behaviour at home were adapted for use in the child's self concepts about sociable-unsociable, attentive-inattentive and settled-restless behaviour at home.

To administer the inventory, the researcher sat next to the child with the form reading each item aloud, pointing to each of the response options. The child responded by marking one option on the dot-point rating scale (low = one dot to high $=$ five dots). The responses formed reliable scales (with Cronbach alpha coefficients $>.70$ ), although there was one exception (therefore the one weak item was unscored). Scores for children's self-concepts about social behaviour at home (with unweighted items) were summed for each aspect, with range (1) unsociable to (5) sociable.

\subsection{Procedure}

The research was approved the University Ethics Committee and State Government Department of Education and Training. Participants were recruited from a suburban school with informed consent of their parents/guardians. Parents were also fully informed about the study and instructed that they would be able to withdraw from the process at any stage.

Trained researchers administered forms to adults at home. To limit discussions among family members, each child was interviewed in a quiet room at school by a trained researcher. The forms were administered using standard procedures, and sessions were brief (less than 20 minutes).

\subsection{Data Analysis}

SPSS for Windows was used for descriptive statistics (i.e., mean, standard deviation, range) and inferential statistics (reliability, correlations, analysis of variance). Conventional standards were used for statistical significance ( $\mathrm{p}<.05)$, and effect sizes were calculated by hand (difference between means divided by the pooled standard deviation). An effect size of 0.4 of sd (or more), and correlations $r>.30$ were considered meaningful (Bornholt, 1997, 2005; Bornholt \& Ingram, 2001; Bornholt \& Piccolo, 2005).

\section{Results}

The results are presented in two parts. Part one describes the diversity of responses and average responses for children's self-concepts and parent reports about children's social behaviour at home. The second part of the results examines any associations between self-concepts and parent ratings of the children's unsociable-sociable, inattentive-attentive and restless-settled behaviour at home.

\subsection{Profiles of child self-concepts and parental reports}

Table 1 describes the reliability of the responses by parents and children. Table 1 also shows the mean, standard deviations and range for self-reports and parent reports of children's social behaviour at home (unsociable-sociable, inattentive-attentive, and restless-settled behaviour). It is important to note that observations cover the full range of social behaviours (e.g., from 1 unsociable to 5 sociable).

\section{INSERT TABLE 1 ABOUT HERE}

On average, parental observations of children's social behaviours are moderate to positive. In particular, parental responses about unsociable-sociable, inattentive-attentive, and restless-settled behaviour are at or above the mid-point of the five-point scale. Table 1 also shows that, on average, children express positive self-concepts about their unsociable-sociable, inattentive-attentive and restless- settled behaviour at home. Self-concepts about social behaviour at home are also above the mid-point of the five-point scales.

It can be seen from the profiles of means in Table 1 that, on average, the group of children tend to be more positive than the group of parents about children's unsociable-sociable behaviour (effect size $0.4 \mathrm{sd}$ ), inattentive-attentive behaviour (effect size $0.5 \mathrm{sd}$ ), and restless-settled behaviour at home (effect size $0.9 \mathrm{sd}$ ).

Table 2 shows the limited influence of age and gender on children's self-concepts and parental reports on children's social behaviour at home. In particular, children's self-concepts and parental reports on children's social behaviour did not vary with the children's age (non-significant correlations $r$ range from .02 to .14). The one exception was a tendency for parents of older children to report somewhat more settled behaviour (weak correlation, $r=.34, p<.05$ ). Table 2 also shows the similarities for girls and boys. Children's self-concepts and parental reports on children's social behaviour at home were not associated with gender (non-significant correlations $r$ ranged from -.18 to .03, using codes 
of 0 boys, 1 girls). Subsequent analyses of child self-report and parental reports of children's social behaviour therefore combined the responses about younger and older girls and boys.

\section{INSERT TABLE 2 ABOUT HERE}

\subsection{Distinct or common perspectives on social behaviour?}

Results show few links between child self-concepts and parent reports on social behaviour at home. For parents and children, the three content areas, unsociable-sociable, inattentive-attentive, and restless-settled behaviours at home were associated with each other $(\mathrm{r}=.6$ to .8$)$. Yet Table 3 highlights the discrete perspectives by children and parents on unsociable-sociable behaviour $(\mathrm{r}=.06 \mathrm{~ns})$, with statistically significant yet weak links for inattentive-attentive behaviour $(\mathrm{r}=.23 \mathrm{p}<.05)$ and discrete perspectives on restless-settled behaviour at home $(\mathrm{r}=.18 \mathrm{~ns})$. In addition, there was an interesting weak link in an off-diagonal cell of Table 3 between child self-concepts of sociable behaviour with parent reports of attentive behaviour $(\mathrm{r}=.32 \mathrm{p}<.05)$.

\section{INSERT TABLE 3 ABOUT HERE}

\section{Discussion}

It appears that, on average, groups of parents consider that children behave moderately well at home. On average, groups of children are also quite positive about their social behaviour at home. It is clear that the profiles cover the full range of children's unsociable to sociable, inattentive to attentive and restless to settled behaviour. The evidence provided a sound basis to examine any links among pairs of children and their parents.

The findings provide sufficient support for the hypotheses. The major finding is that these reliable reports provide useful evidence that the views of parents and their children are not necessarily linked. In other words, pairs of children with their parents have distinct perspectives about the child's social behaviour at home. We can conclude that when considering children's social behaviour in the context of the home, the findings do not support common understandings about children's social behaviour.

\subsection{Contribution to the literature on self-concepts and parental reports}

From the study, we found that using the parallel dimensions scale did not increase the agreement between the pairs of parent reports and self-concepts on children's social behaviour at home. This study provides persuasive evidence on the perspectives of parent and children about the children's social behaviour. These findings are consistent with previous studies by Gresham \& Elliott (1990) with several substantial samples of children using the Social Skills Rating System. The works of Gresham \& Elliott (1990), Achenbach, McConaughy, \& Howell (1987), Herjanic \& Reich (1982) and the present findings, lead us to conclude that parents and their children may agree about easily observable behaviours such as factual events (e.g., whether the child was hospitalized) and some specific behaviours (e.g., an incident of fighting or a temper tantrum), yet child and parental reports have distinct perspectives across dimensions of social behaviour (such as the behaviours covered here by RBRI dimensions of unsociable-sociable, inattentive-attentive, restless-settled behaviour) (see also Gresham \& Elliott, 1990).

The results of the present study provide rather interesting information concerning the distinct rather than common perspectives between parental reports and child self concepts about social behaviours at home that are specifically salient to children's learning and development. According to Achenbach and Edelbrock et al. (Achenbach et al., 1987; Edelbrock, Costello, Dulcan, Conover, \& Kala, 1986), distinct parent and child reports, in itself, does not indicate that one is wrong and the other is right. Instead, this represents a consequence of their particular experiences. Some researchers emphasise that children have independent views about themselves, as well as of how they function in specific roles or under certain constraints (Edelbrock et al., 1986). The limited associations between child self concepts and parental reports on children's unsociable-sociable, inattentive-attentive, and restless-settled behaviour at home suggest that each informant contributes understanding of the situation that is not accounted for by the other person.

We conclude that children's self-concepts and reports by parents are not substitutes for each other. The findings add to the work on context and position-taking by Bornholt (e.g., Bornholt \& Rhodes, 2006) that children's self-concepts, parent, teacher and clinical reports are important additions to and not substitutes for systematic observations of children's social behaviour at home and at school.

The findings have the potential to make a broader contribution to self-concept construction theory, in particular on the construct validity of self-concept responses. The results add to evidence on the fundamental nature of self-concepts, in support of self- and categorization theories (see classic works of Tajfel and others, e.g., Maras, Lewis, \& Simonds, 1999; Tajfel, 1978). The valid distinctions rather than common perspectives by children and parents need to be considered with other work on the nature of self-concepts. What children think about themselves - as self-concepts - is in addition to rather than in place of actual performance, characteristics and behaviours, along with recent work that adds views of a clinician and trained observers (see Bornholt, 2005; Bornholt \& Rhodes, 2006; Wigfield \& Eccles, 2000), we can challenge conventional views that development of self-concepts comes from direct reflection on behaviour or reflected 
appraisals of other people, especially significant others. In so called 'mirror theory' the self-concept should be positively related to the views of important other people. Instead, findings from the present study suggest parental reports about the child have limited direct impact on children's developing conception of self (see also reports on pathways through child self-disclosure and parental expectations of the child, Bornholt \& Goodnow, 1999; Seginer \& Vermulst, 2002).

\subsection{Strengths and limitations of the design of the study}

Interpretations of findings need to account for the strengths and any limitations in the design. The first comment is that limited sample size has distinct advantages. We used a small sample and checked that commonly reported influences by age and gender were limited. Defining the location also allowed us to control broader socio-economic factors. For example, socio-economic factors may differentially influence reported behaviours (Hattie, 1992; Kline, 2000; Theunissen et al., 1998). In any study of social behaviours, where the contexts matter, we do not consider that we are not free to apply these findings from one place to another. The findings show that it would be worthwhile to extending our work - to other places using the same materials and procedures.

The outcomes raise an important feature of this study - the need to use matched instruments. One of the strengths of this design is that parent and child reports used the same content items from the Rowe Behaviour Rating Inventory (Rowe \& Rowe, 1995; 1997), with repeated items and child-appropriate techniques drawn from the ASK-KIDS Inventory (Bornholt, 2005). The outcomes mean that we may need to re-consider the findings from previous research that used different materials for child and parent.

The third comment is that our content covered a spectrum of social behaviours - unsociable-sociable, inattentive-attentive, restless-settled behaviour. In prevention as well as intervention programmes it is important to extend our observations beyond the target problem behaviours (see Achenbach et al., 1987; Rowe \& Rowe, 1999). This raises the idea that content and context shift the domain of the particular questions put to parents and children to such an extent that findings from diverse studies about children's social behaviour are no longer comparable.

Finally, the carefully drawn sample is sufficient for the analyses (see Kline, 2000 on $r>.3$ as minimal meaningful links) given the care of a trial for inventories with two independent observers and video checks in training fieldworkers (see Achenbach, McConaughy, \& Howell, 1987). Hoyle (1999) also argues for reliance on estimates of the strength of the parameters (such as effect size). Statistical significance is an important yet preliminary observation that relies largely on sample size. It is also important to note that observations of three social behaviours as within-person variability strengthens the design. In addition, participants were sampled age and gender, to increase representation for this location. It is important to note that long-standing research shows substantial similarities for ratings by mothers and fathers (Achenbach et al., 1987), and the age and gender of the children do not systematically alter parent-child concordance for child behaviours either alone or in conjunction with one another (e.g., Achenbach et al., 1987; Bornholt, 2005; Hoyle, 1999).

\subsection{Further research and applications to practice}

The findings yield useful information that contributes to theoretical knowledge on social skills assessments and also is applicable to working with children in early or preventive intervention programs. Both positive self-concept and social behaviour may be potentially beneficial in promoting positive child outcomes (Bornholt, 2005; Merrell et al., 1993). The weak links between ratings by different informants pose a challenge for clinical categorizing of social-unsocial behaviours of children presented in a home setting. Failure to account for how children think about their own social behaviours at home may lead to inappropriate or at best inefficient training programs. Educators and clinicians can make good use of this information to tailor education and counselling services to the needs of individuals who have problems in either social behaviours or low self-concepts about appropriate social behaviours. Furthermore, it may be worthwhile following up apparent weak links between parental reports on child's attentiveness and other aspects of children's social behaviour. What are supposed pathways from attentiveness to other social behaviours?

This study suggests several directions for future research. The two sources used in this study (parent behaviour-ratings and child self-reports from RBRI and ASK-KIDS inventories) provide a strong basis for substantial multi-method, multi-source and multi-setting observations of children's social behaviours. To counter the common practice of using parent and teacher reports to stand in for children's behaviour or self report, there is a pressing need for self- and parental reports along with direct behavioural observation and behaviour ratings from children and others (teacher, clinician, peer and parent) across different settings including school, home, play and clinic. Together, the evidence would highlight how significant others and the children themselves play such vital roles in the children's learning and development.

We conclude that parental reports of their children's social skills do not set a so-called 'gold standard'. Such reports may not be used to 'stand in for' children's actual social behaviours (see Achenbach et al., 1987; Bornholt \& Rhodes, 2006). On the contrary, parental reports and child self-reports are key elements that inform our critical orientations with 
respect for the voices and perspectives of children, which are in addition to the views of their parents or primary care-givers.

\section{Acknowledgements}

To the children, parents and teachers, for their insights and co-operation; with our thanks for fieldwork assistance to Nicki Brake, Tracy Rhodes, Madeline Parnell, Bree Hulme, Anna Piccolo, Carly Murphy, Carolyn Storrier, Kathryn Timmis, Nicole Martin, Anna Varejlian, particularly to Therese Levins, Lesley Russell and Pam Maras for their professional advice, and for comments on earlier versions of the paper by Ray Debus and Andrew Martin. The project was funded by a University grant to Laurel Bornholt, and an earlier report was presented by Haibin Li at the 2007 Australian Association for Research in Education conference.

\section{References}

Achenbach, T. M., McConaughy, S. H., \& Howell, C. T. (1987). Child/ adolescent behavioural and emotional problems: implications of cross-informant correlations for situational specificity. Psychological Bulletin, 101, 213-232.

Australian Bureau of Statistics ABS. (2006). Socio-Economic Index for Areas. Canberra: Australian Bureau of Statistics.

Bornholt, L. J. (1997). Aspects of Self Knowledge about activities with young children. Every Child, 3, 8-9.

Bornholt, L. J. (2005). ASK-KIDS Self Concept Inventory. Melbourne: ACER Press.

Bornholt, L. J., \& Goodnow, J. J. (1999). Cross-generation perceptions of academic competence: Parental perceptions and adolescent self disclosure. Journal of Adolescent Research, 14, 427-446.

Bornholt, L. J., \& Ingram, A. (2001). Personal and social identity in children's self-concepts about drawing. Educational Psychology, 21, 151-167.

Bornholt, L. J., \& Piccolo, A. (2005). Individuality, belonging and children's self-ceoncepts: A Motivational Spiral Model of Self evaluations, performance and participantion in physical activities. Applied Psychology: An International Review, 54, 516-537.

Bornholt, L. J., \& Rhodes, T. R. (2006). Position and perspective on social behaviour for learning: Re-thinking unsociable-sociable, inattentive-attentive, restless-settled behaviour. Paper presented at the international Institute for the Rights of the Child Conference in Sion, Switzerland.

Brown, G. L., Mangelsdorf, S. C., Agathen, J. M., \& Ho, M. (2008). Young children's psychological selves: Convergence with maternal reports of child personality. Social Development, 17(1), 161-182.

Cook, W. L., \& Douglas, E. M. (1998). The looking-glass self in family context: A social relations analysis. Journal of Family Psychology, 12, 299-309.

Cremeens, J., Eiser, C., \& Blades, M. (2006). Factors influencing agreement between child self-report and parent proxy-reports on the Pediatric Quality of Life Inventory ${ }^{\mathrm{TM}} 4.0$ (PedsQL ${ }^{\mathrm{TM}}$ ) generic core scales. Health Qual Life Outcomes, 4(58), 1-8.

Davis-Kean, P., \& Sandler, H. M. (2001). A Meta-analysis of Measures of Self-Esteem for Young Children: A Framework for Future Measures. Child Development, 72, 887-906.

Edelbrock, C. S., Costello, A. J., Dulcan, M. K., Conover, N. C., \& Kala, R. (1986). Parent-child agreement on child psychitric symptoms assessed via structured interview. Journal of Child Psychology and Psychitry, 27(2), 181-190.

Gresham, F. M. (1986). Conceptual issues in the assessment of social competence in children. In P. S. Strain, M. J. Guralnick \& H. M. Walker (Eds.), Children's social behavior: Development, assessment, and modification. Chapter 4 (p.143-179). Orlando: Academic Press, INC.

Gresham, F. M., \& Elliott, S. N. (1990). Social skills rating system. Circle Pines, MN: American Guidance Service.

Harter, S. (1988). Causes, correlates and the functional role of global self-worth: A life-span perspective. In J. Kolligian \& R. Sternberg (Eds.), Integrative processes and socialization: Early to middle childhood. Hillsdale, NJ: Erlbaum.

Hattie, J. (1992). Self concept. Hillsdale:NJ: Erlbaum.

Herjanic, B., Herjanic, M., Brown, F., \& Wheatt, T. (1975). Are Children Reliable Reporters? Journal of Abnormal Child Psychology, 3(1), 41-48.

Herjanic, B., \& Reich, W. (1982). Development of a structured psychiatric interview for children: agreement between child and parent on individual symptoms. Journal of Abnormal Child Psychology, 10, 307-324. 
Hoy, E. A., Sykes, D. H., Bill, J. M., Halliday, H. L., McClure, B. G., \& Reid, M. M. (1992). The social competence of very-low-birthweight children: teacher, peer, and self-perceptions. Journal of Abnormal Child Psychology, 20(2), 123-151.

Hoyle, R. H. (1999). Statistical strategies for small sample research. Thousand Oaks, Calif: Sage Publications.

James, W. (1890). The principles of psychology. New York: Holt.

Kline, P. (2000). The handbook of psychological testing (2nd edition). London: Routledge.

Linder, T. W. (1993). Transdiscipinary play based assessment. Baltimore, MD: Paul H. Brookes Publishing.

Maras, P., Lewis, P., \& Simonds, L. (1999). Elephants, donuts and hamburgers: young children co-operating to co-operate and co-operating to compete in two primary schools. Educational Psychology Review, 19(3), 245-258.

Marsh, H. W., \& Craven, R. G. (1991). Self-Other agreement on the multiple dimensions of preadolescent self-concept: Inferences by teachers, mothers, and fathers. Journal of Educational Psychology, 83(3), 393-404.

Marsh, H. W., Debus, R., \& Bornholt, L. J. (2005). Validating young children's self-concept responses: Methodological ways and means to understand their responses. In D. M. Teti (Ed.), Handbook of Research Methods in Developmental Psychology. Chapter 8 (pp.138-160). Blackwell Publishers.

Merrell, K. W., Cedeno, C. J., \& Johnson, E. R. (1993). The relationship between social behavior and self-concept in school settings. Psychology in the Schools, 30, 293-298.

Moretti, M. M., Fine, S., Haley, G., \& Marriage, K. (1985). Childhood and adolescent depression: Child-report versus parent-report information. Journal of the American Academy of Child Psychiatry, 24(3), 298-302.

Prior, M., Smart, D., Sanson, A., Pedlow, R., \& Oberkaid, F. (2001). Transient Versus Stable Behavior Problems in a Normative Sample: Infancy to School Age. Journal of Paediatric Psychology, 17, 423-443.

Rowe, K. S., \& Rowe, K. J. (1995). RBRI Profile User's Guide: The University of Melbourne.

Rowe, K. S., \& Rowe, K. J. (1997). Norms for parental rating on Connors' Abbreviated Parent-Teacher Questionaire: Implications for the design of Behavioural Rating Inventories and analyses of data derived from them. Journal of Abnormal Child Psychology, 25, 425-451.

Rowe, K. S., \& Rowe, K. J. (1999). Investigating the relationship between students' attentive-inattentive behaviors in the classroom and their literacy progress. International Journal of Educational Research, 31(1-2), 31-48.

Russell, L., Bornholt, L., \& Ouvrier, R. (2002). Brief cognitive screening and self concepts for children with low intellectual functioning. British Journal of Clinical Psychology, 41, 93-104.

Seginer, R., \& Vermulst, A. (2002). Family environment, educational aspirations and academic achievement in two cultural settings. Journal of Cross-Cultural Psychology, 33, 540-558.

Shrauger, J. S., \& Schoeneman, T. J. (1979). Symbolic interactionist view of self-concept: Through the glass darkly. Psychological Bulletin, 86, 549-573.

Stormont, M. (2001). Preschool family and child characteristics associated with stable behaviour problems in children. Journal of Early Intervention, 24(4), 241-251.

Tajfel, H. (1978). The psychological structure of intergroup relations. In H. Tajfel (Ed.), Differentiation between social groups: studies in the social psychology of intergroup relations. London, UK: Academic Press.

Theunissen, N. M., Vogels, T., koopman, H. M., Verrips, G. H., Zwinderman, K. A. H., Verloove-Vanhorick, S. P., et al. (1998). The proxy problem: child report versus parent report in health-related quality of life research. Quality of Life Research, 7, 387-397.

Wigfield, A., \& Eccles, J. S. (2000). Expectancy value theory of achievement motivation. Contemporary Educational Psychology, 25, 68-81.

Zentner, M., \& Renaud, O. (2007). Origins of adolescents' ideal self: An intergenerational perspective. Journal of Personality and Social Psychology, 92(3), 557-574. 
Table 1. Profiles of child self-concepts and parental reports about children's unsociable-sociable, inattentive-attentive, restless-settled behaviour at home

\begin{tabular}{|c|c|c|c|c|c|}
\hline context & social behaviour & mean $^{a}$ & sd & range & alpha \\
\hline \multirow{3}{*}{ children } & unsociable-sociable $^{*}$ & 3.8 & 0.9 & $1.0-5.0$ & 0.7 \\
\cline { 2 - 6 } & inattentive-attentive $^{*}$ parents & 3.6 & 1.1 & $1.0-5.0$ & 0.7 \\
\cline { 2 - 6 } & restless-settled $^{\text {a }}$ & 3.8 & 1.0 & $1.0-5.0$ & 0.7 \\
\cline { 2 - 6 } & unsociable-sociable $^{*}$ inattentive-attentive $^{*}$ & 3.4 & 1.1 & $1.0-5.0$ & 0.9 \\
\cline { 2 - 6 } & restless-settled & 2.9 & 1.0 & $1.0-5.0$ & 0.8 \\
\hline
\end{tabular}

\section{Notes}

a. Inventories of parental reports and child self-reports range from 1 (low) to 5 (high)

b. Item 4 was not a satisfactory indicator of children's self concepts of restless-settled behaviour at home, and was excluded from analysis.

Table 2. Influence of age and gender on children's self-concepts and parental reports of children's social behaviours at home

\begin{tabular}{|c|c|c|c|}
\hline correlations $^{a}$ & social behaviour at home & age & gender $^{b}$ \\
\hline \multirow{3}{*}{ children } & unsociable-sociable & .05 & -.06 \\
\cline { 2 - 4 } & inattentive-attentive & .02 & -.18 \\
\cline { 2 - 4 } & restless-settled & .04 & .07 \\
\hline \multirow{3}{*}{ parents } & unsociable-sociable & .14 & .03 \\
\cline { 2 - 4 } & inattentive-attentive & .06 & -.01 \\
\cline { 2 - 4 } & restless-settled & .02 \\
\hline
\end{tabular}

\section{Notes}

a. Meaningful associations are $\mathrm{r} \geq .3$ (see Kline, 2000)

b. For the correlational analysis, gender is coded 0 boys and 1 girls

Table 3. Associations a (r) between children's self concepts and parental report on children's social behaviour at home

\begin{tabular}{|c|c|c|c|}
\hline \multirow[b]{2}{*}{ Context } & \multicolumn{3}{|c|}{$\underline{\text { Parental reports }}$} \\
\hline & $\begin{array}{c}\text { Unsociable- } \\
\text { Sociable }\end{array}$ & $\begin{array}{c}\text { Inattentive- } \\
\text { Attentive }\end{array}$ & $\begin{array}{l}\text { Restless- } \\
\text { Settled }\end{array}$ \\
\hline \multicolumn{4}{|l|}{ Child self-concepts } \\
\hline \multirow{6}{*}{$\begin{array}{l}\text { Unsociable-Sociable } \\
\text { Inattentive-Attentive } \\
\text { Restless-Settled }\end{array}$} & \multicolumn{2}{|c|}{0.06} & $0.32 *$ \\
\hline & \multicolumn{3}{|c|}{0.03} \\
\hline & \multirow[t]{2}{*}{0.09} & & 0.23 \\
\hline & & 0.05 & \\
\hline & \multicolumn{2}{|c|}{0.18} & $0.28 *$ \\
\hline & & 0.18 & \\
\hline
\end{tabular}

\section{Notes}

a. Meaningful associations are $r \geq .3$ (see Kline, 2000).

b. Asterisks indicate the statistical significance of correlations, $* \mathrm{p}<.05$ 